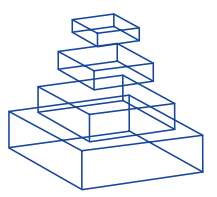

\title{
Contribution of subcortical structures to cognition assessed with invasive electrophysiology in humans
}

\author{
Thomas F. Münte ${ }^{1, \dagger}$, Marcus Heldmann², Hermann Hinrichs², \\ Josep Marco-Pallares ${ }^{1}$, Ulrike M. Krämer ${ }^{1}$, Volker Sturm ${ }^{3}$ and \\ Hans-Jochen Heinze ${ }^{2}$ \\ 1 Department of Neuropsychology, University of Magdeburg, Magdeburg, Germany. \\ 2 Department of Neurology II, University of Magdeburg, Magdeburg, Germany. \\ 3 Department of Stereotactic and Functional Neurosurgery, University of Cologne, Cologne, Germany.
}

Edited by:

Robert T. Knight, University of California Berkeley, USA

\section{Reviewed by:}

Maurizio Corbetta,

Washington University, USA

George R. Mangun, University

of California Davis, USA

\section{Correspondence:}

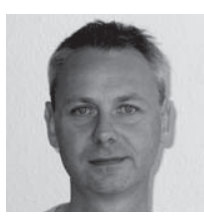

Thomas Münte is Professor of Neuropsychology at the University of Magdeburg. Following his medical studies in Göttingen, Germany, he trained as a neurologist at the Medical School Hannover, Germany. During the past 25 years he has conducted research on many different topics in cognitive neuroscience, ranging from early work on visual attention to bilingual language processing. Among his recent interests is the neural implementation of executive and action monitoring processes. In addition to his research, he is active as a clinical neurologist. thomas.muente@medizin. uni-magdeburg.de

Implantation of deep brain stimulation (DBS) electrodes via stereotactic neurosurgery has become a standard procedure for the treatment of Parkinson's disease. More recently, the range of neuropsychiatric conditions and the possible target structures suitable for DBS have greatly increased. The former include obsessive compulsive disease, depression, obesity, tremor, dystonia, Tourette's syndrome and clusterheadache. In this article we argue that several of the target structures for DBS (nucleus accumbens, posterior inferior hypothalamus, nucleus subthalamicus, nuclei in the thalamus, globus pallidus internus, nucleus pedunculopontinus) are located at strategic positions within brain circuits related to motivational behaviors, learning, and motor regulation. Recording from DBS electrodes either during the operation or post-operatively from externalized leads while the patient is performing cognitive tasks tapping the functions of the respective circuits provides a new window on the brain mechanisms underlying these functions. This is exemplified by a study of a patient suffering from obsessive-compulsive disease from whom we recorded in a flanker task designed to assess action monitoring processes while he received a DBS electrode in the right nucleus accumbens. Clear error-related modulations were obtained from the target structure, demonstrating a role of the nucleus accumbens in action monitoring. Based on recent conceptualizations of several different functional loops and on neuroimaging results we suggest further lines of research using this new window on brain functions.

Keywords: deep brain stimulation, action monitoring, motivation, subcortical nuclei, memory, nucleus accumbens, nucleus subthalamicus, electrophysiology

\section{INTRODUCTION}

The first two decades of cognitive neuroscience have been a success story that is intimately linked to the development of sophisticated models of cognitive functions but no less so to the improvements in brain imaging procedures. Functional magnetic resonance imaging (fMRI) and surface electrophysiology (event-related potentials and time-frequency analyzed EEG) have provided a detailed picture of the brain mechanisms underlying cognition. On the other hand, there are still a number of remaining scotomata in our view on the brain, for example the relative blindness of EEG-derived measures to activity coming from subcortical structures and the low temporal resolution of fMRI limiting its use for chronometric analyses.

Recently, the implantation of electrodes for deep brain stimulation (DBS) of subcortical nuclei as a 
therapy for neuropsychiatric disorders has opened a new window on brain functions (Ashby and Rothwell, 2000). Importantly, most patients are awake during the implantation for clinical reasons. Thus, it is feasible to record electrophysiological activity from the target structure during the operation or from externalized leads post-operatively, i.e. before the electrodes are connected with the stimulator which is located beneath the pectoral muscle, while the patients can perform various psychological tasks.

A number of groups have taken up this opportunity and have recorded surface activity and depth activity related to motor behavior in stimulated patients. They have concentrated on the physiological effects of DBS of the subthalamic nucleus in Parkinson's disease (PD). For example, an increase in amplitude of the surface recorded contingent negative variation (CNV) was found with stimulation electrodes 'on' relative to the 'off' condition (Gerschlager et al., 1999). As the CNV indexes at least in part motor preparatory processes, this finding was interpreted as indicative of therapy-related improvement of the function of frontal and premotor areas. Similarly, the finding of Devos et al. (2006) that stimulation of the STN also normalizes abnormally reduced and delayed motor-related oscillatory activity in PD can be interpreted in terms of a normalization of motor functions. A recent review by Valls-Sole et al. (2008) summarizes the effects of stimulation on cortical and subcortical (e.g. blink reflex) motor behaviours in PD. By contrast, the goal of the current article is to highlight the possibilities of depth recordings for the elucidation of cognitive functions.

In particular, the recent extension of the DBS technique to structures like the nucleus accumbens or the posterior inferior hypothalamus, i.e. brain structures that are intimately related to motivation, learning and performance monitoring calls for research efforts addressing these functions. A summary of targeted structures and disorders is given by Table 1.

\section{STRUCTURES, LOOPS, AND FUNCTIONS}

A seminal concept introduced in the 1980s proposed that information processing in several important domains is supported by frontal-basal ganglia loops organized in parallel pathways throughout the basal ganglia (Alexander et al., 1986; Middleton and Strick, 2000). This concept has been broadened considerably over the past 20 years and loop-like organizational patterns have been described for a number of other regions. Importantly, such models help us to make reasonable predictions about the contribution of subcortical structures to information processing and to test these using intracranical recordings from DBS electrodes (see Figure 1).

The three greatly simplified circuits represent networks that are currently accessible with recordings from DBS electrodes. Left: The learning circuit was adapted from work by Lisman and Grace (2005) who argue that the hippocampus and the midbrain dopaminergic neurons form a functional loop. Novel information that is not stored in long-term memory activates the hippocampus from where the novelty signal is sent through the subiculum, $\mathrm{Ncl}$ accumbens, and ventral pallidum to the dopaminergic midbrain inducing noveltydependent firing of these cells. This firing results in release of dopamine in the hippocampus where it enhances long-term potentiation and as, as a consequence, learning. Of this loop currently the $\mathrm{Ncl}$ accumbens has been selected as a target for DBS. Middle: The motivation circuit was adapted from work by Swanson (2000) and Kelley (2004). The hypothalamus is a main center for digestive, defensive and reproductive, i.e. basic motivated behaviors and besides visceral and autonomic outputs (not shown) projects to the dopaminergic

Table 1 | Brief summary of targeted brain structures and neuropsychiatric conditions.

\begin{tabular}{|c|c|c|}
\hline Structure & Disorder & Example reference \\
\hline Ncl. Subthalamicus & Parkinson's disease (PD) & Benabid et al. $(2005,2007)$ \\
\hline Globus pallidus int. & Dystonia, PD & Yu and Neimat (2008) \\
\hline Ventral intermediate part of the thalamus & Tremor, PD & Diederich et al. (2008) \\
\hline Centre Median Nucleus/Parafascicular (CM/PF) Complex & $\mathrm{PD}$ & Peppe et al. (2008) \\
\hline Unspecific thalamocortical system & Minimally conscious state & Schiff et al. (2007) \\
\hline Pedunculopontine nucleus & $\mathrm{PD}$ & Androulidakis et al. (2008), Zrinzo et al. (2007) \\
\hline Zona incerta & $\mathrm{PD}$ & Plaha et al. (2006) \\
\hline Posterior inferior hypothalamus & Cluster headache, obesity & Bussone et al. (2007) \\
\hline $\mathrm{Ncl}$ accumbens & OCD, depression, addiction & Kühn et al. (2007), Schlaepfer et al. (2008), Sturm et al. (2003) \\
\hline
\end{tabular}




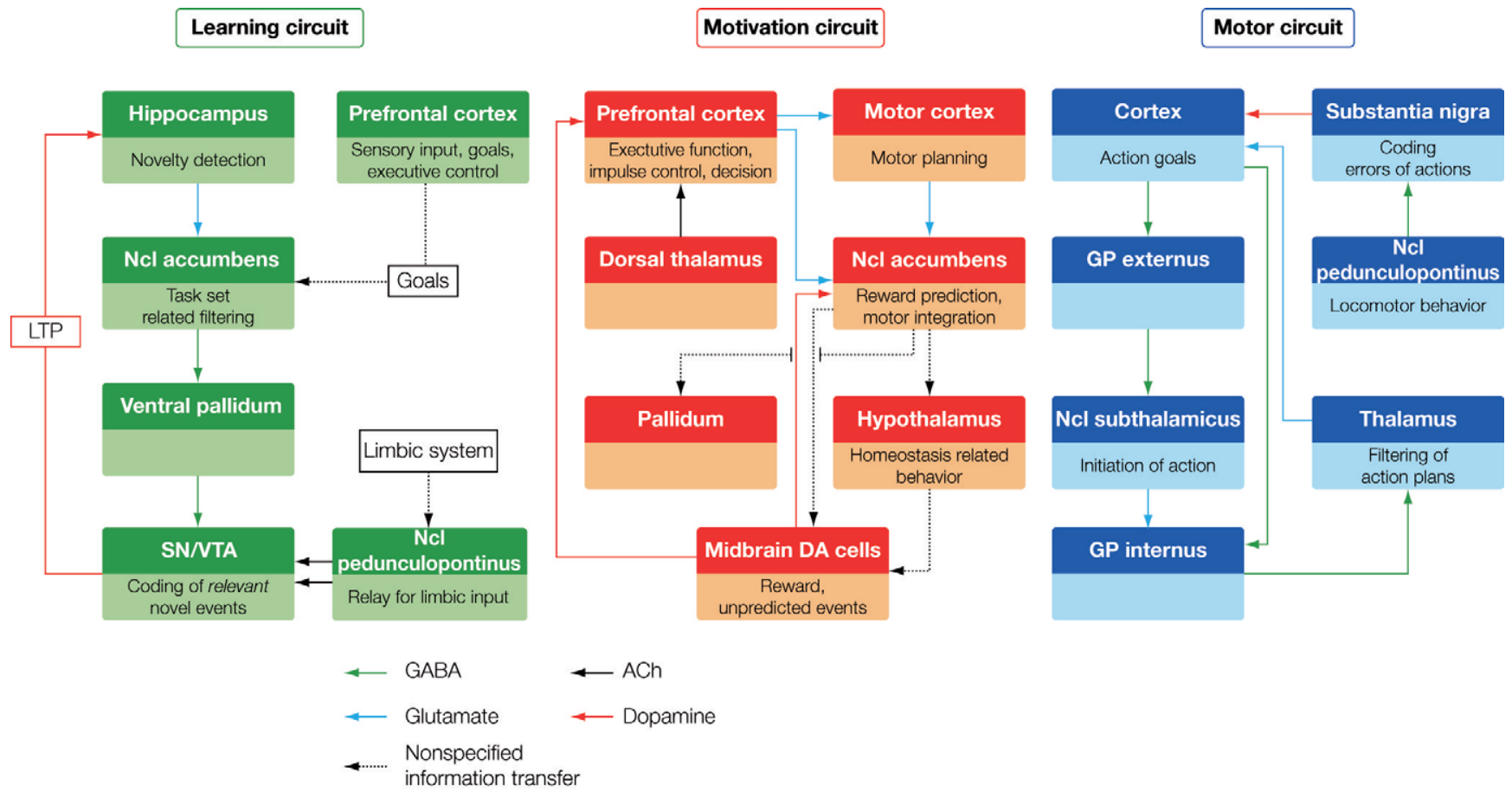

Figure 1 | Target brain circuits for the investigation with recordings from DBS electrodes.

midbrain. The expectation and consumption of primary and secondary rewards leads to an activation of the midbrain and in turn to dopaminergic stimulation of the $\mathrm{Ncl}$ accumbens and the prefrontal cortex. The $\mathrm{Ncl}$ accumbens integrates rewards and appears to weigh information coming from limbic areas (amygdale, hippocampus, not shown) and prefrontal cortex in order to direct behavior. Of this network currently the hypothalamus and the $\mathrm{Ncl}$ accumbens are targeted by DBS procedures. Right: The motor circuit is based on work by Alexander et al. (1986). Its functions have recently been addressed in modeling work by Frank (2006) which makes very specific predictions as to the behaviors of the different components of this circuit in motor tasks (e.g., GoNogo task). Of this loop the subthalamic nucleus, the globus pallidus internus and several parts of the thalamus (most commonly the VIM nucleus) are currently targeted by DBS.

\section{POTENTIAL QUESTIONS AND PARADIGMS}

In line with the proposal by Lisman and Grace (2005) illustrated in Figure 1 (left), a number of neuroimaging studies have explored the contribution of the dopaminergic midbrain to novelty processing and memory formation. For example Wittmann et al. (2007) presented symbolic cues that predicted either novel or familiar images of scenes with $75 \%$ validity and showed midbrain activation by cues predicting novel images as well as by unexpected novel images that followed familiarity-predictive cues. Moreover, an anticipatory novelty response was found in the hippocampus which was associated to enhanced encoding of novel events. In a rewardmotivated memory formation task (Adcock et al., 2006) high-reward cues preceding remembered but not forgotten scenes activated the ventral tegmental area, nucleus accumbens, and hippocampus, i.e. the 'memory circuit' depicted in Figure 1 (left). Such paradigms exploring the effects of novelty and reward on memory formation could be adapted easily to the experimental requirements of recording from DBS electrodes located in the nucleus accumbens. In particular the temporal dynamics of the depth responses in relation to the novelty stimulus would be of interest.

Efficacy in probabilistic learning tasks has been shown to vary as a function of the state of the dopaminergic system in Parkinson's disease (Frank et al., 2004) with functional imaging demonstrating involvement of the midbrain and the ventral striatum in the learning of stimulus response associations (Marco-Pallares et al., 2007). Interestingly, modelling work by Frank (2006) has stressed the role of the subthalamic nucleus in probabilistic learning. In particular, models with lesions of the subthalamic nucleus were impaired at high conflict choices (i.e. between two positively associated responses) and were equally likely to choose the $70 \%$ and $80 \%$ response. This suggests that intracerebral recordings of both, $\mathrm{Ncl}$ accumbens and $\mathrm{Ncl}$ 
subthalamicus should be revealing. In particular activity in the subthalamic nucleus could be used to test the model of Frank (2006).

The ventral striatum including the $\mathrm{Ncl}$ accumbens has been shown to be involved in reward anticipation (Cohen et al., 2007; Yacubian et al., 2006) and consumption (McClure et al., 2004). Because of their low temporal resolution, fMRI investigations do not allow to temporally dissect the neurophysiological mechanisms involved in anticipation and consumption of rewards (Dillon et al., 2008), which calls for intracerebral recordings from the $\mathrm{Ncl}$ accumbens in reward tasks.

With regard to the homeostatic functions of the hypothalamus, a number of simple paradigms have found activations of the hypothalamus to food (Smeets et al., 2005) and sexually significant (Karama et al., 2002) stimuli. Recordings from the hypothalamus might shed further light on the temporal dynamics of these basic housekeeping functions.

With regard to the motor circuit, a number of tasks involving response conflict (Wendt et al., 2007), a go/nogo (Falkenstein et al., 1999; Sasaki and Gemba, 1986), or a stop manipulation (Krämer et al., 2007) are promising. Or particular interest is the fact that the motor system can be tapped at different levels (e.g. subthalamic nucleus, globus pallidus internus, VIM nucleus of the thalamus).

\section{THE SIGNALS}

The most promising signal for cognitive investigations from subcortical structures is the local field potential (LFP) which is the band-pass filtered (usually between 1 and 150 to $300 \mathrm{~Hz}$ ) spontaneous electrical activity recorded with micro- or macro-electrodes. The LFP comprises mostly the summated synchronized EPSPs and IPSPs from within $0.5-3 \mathrm{~mm}$ of the electrode-tip (Juergens et al., 1999; Magill et al., 2004a,b). Microelectrodes can also be used to record multi-unit spike activity (typical filter settings $0.5-10 \mathrm{kHz}$ ), but such recordings have not yet been explored with regard to cognitive processes. Importantly, Kühn et al. (2005) have shown by simultaneous recordings of LFP and multiunit spikes and subsequent spike-triggered averaging of the LFP that the discharges of neurons in subthalamic nucleus were locked to beta oscillations in the LFP. This further strengthens the assumption that the LFP is reflecting the physiological status of the target structure.

A critical issue of recording from subcortical structure is the choice of reference electrode. While some researchers have used a scalp reference (Dinner et al., 2002), bipolar recordings between either the different contacts of the DBS electrode or the electrode-tip and the guiding tube (see case example in An Example: Action Monitoring and The Ncl Accumbens) are preferable, as this avoids contamination of the depth signals by cortical EEG (Wennberg and Lozano, 2006).

The analysis of the LFP can either be in the timedomain by performing event-related averaging similar to surface ERPs or in the frequency domain, e.g. by performing wavelet transforms (see, e.g., MarcoPallares et al., 2008). Further options include the calculation of frequency specific coherence between the depth signal and recordings obtained on the surface of the scalp. An interesting example for this approach is the work of Fogelson et al. (2005) who recorded local field potentials from the subthalamic area in Parkinson patients and found regionally specific coherence such that coherence in the theta-band was predominantly seen for mesial and lateral surface electrodes, whereas alpha and lower beta coherence involved the mesial and ipsilateral motor areas, and finally upper beta coherence was observed mainly for electrodes over the midline cortex. Moreover, the temporal relationship between depth and surface activity (calculated from the phase of the activity) was different in that the depth activity either led surface activity or vice versa. This suggested several functional loops between the subthalamic nucleus and the cortical motor regions defined by their frequency, topographical and temporal features. Application of this approach or more recent extensions, such as Granger causality (Astolfi et al., 2006; Supp et al., 2007) to simultaneous depth/surface recordings in cognitive tasks might greatly improve our knowledge of the task-dependent functional relations between subcortical and cortical areas.

\section{AN EXAMPLE: ACTION MONITORING AND THE NCL ACCUMBENS}

A full account of this case report can be found in Münteet al.(2008).Starting point of thisinvestigation have been theoretical accounts (Holroyd and Coles, 2002) and experimental investigations in animals (Schultz et al., 1997, Schultz, 2006) as well as humans (Krämer et al., 2007) that stress the role of dopaminergic signals in performance monitoring. Given the fact that the midbrain dopaminergic system projects to the medial frontal cortex and to the Ncl accumbens and, furthermore, that the $\mathrm{Ncl}$ accumbens has been proposed to serve as an integrator of limbic and prefrontal input using the dopaminergic signals to regulates their balance in goal-directed behaviour (Goto and Grace, 2005; Grace, 2000; Grace et al., 2007), we hypothesized that the dopaminergic error signal should be detectable in the local field potential from the Ncl accumbens. A simple experiment, yielding sufficient numbers of performance errors in a very short period of time ( $\sim 5 \mathrm{~min})$ and therefore ideal for intraoperative recordings, is the Eriksen flanker task (see Figure 2A). By presenting congruent and incongruent stimuli and by imposing an RT deadline a 
high proportion of errors is obtained in normal participants and patients. If electrophysiological activity is averaged time-locked to the error, a mediofrontal phasic negativity with a maximum at about $50 \mathrm{~ms}$ is obtained, the error-related negativity (ERN). Source modeling studies have revealed the anterior cingulate cortex as the site of the main generator of the ERN (Luu and Tucker, 2001) which coincides with functional neuroimaging that have obtained errorrelated activations in the anterior cingulate cortex and adjacent pre-SMA, as well (Ullsperger and von Cramon, 2003).

The study patient was a 39-year-old male student who had been suffering from severe and therapyrefractory OCD (ICD 10 classification: F42.2) since age 11. All standard pharmacological and psychotherapeutic interventions had been unsuccessful and there were no further neuropsychological problems in addition to OCD. The patient was tested on the day prior to the operation to familiarize him with the task and to record ERPs in a standard session and twice during the operation, once with the active electrode situated $5 \mathrm{~mm}$ above and a second time with the electrode directly within the right

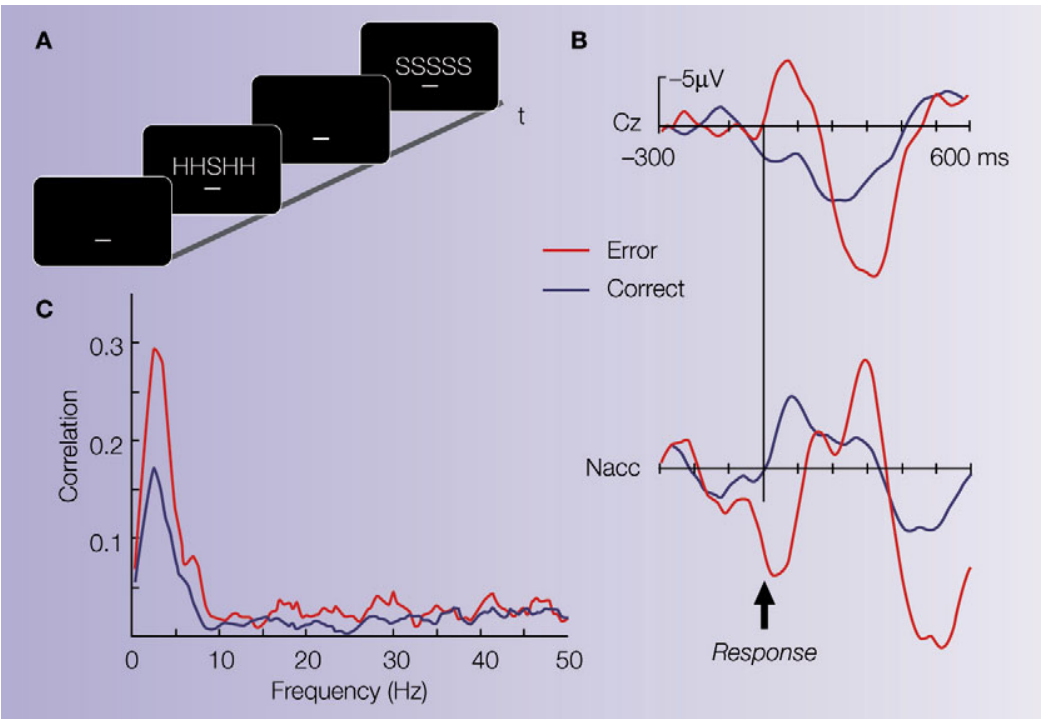

Figure 2 | Illustrative case. (A) The Eriksen flanker task requires to respond to the center letter of a 5-letter array with either a left-hand (for letter $\mathrm{H}$ ) or right-hand response (letter S). Incongruent trials (either HHSHH or SSHSS) increase the number of errors produced by the participant. (B) Averaged ERP from the electrode site $\mathrm{Cz}$ (reference at the right mastoid process) and averaged LFP activity from the Ncl accumbens (stainless macro-electrode contact, reference: guiding tube of electrode). The surface electrode shows an error related negativity (ERN). Ncl accumbens activity similarly shows an error-related modulation which preceded the surface activity by $\sim 40 \mathrm{~ms}$. (C) Coherence between the contact in the $\mathrm{Ncl}$ accumbens and the $\mathrm{Cz}$ electrode: Coherence is a measure of the degree to which it is possible to linearly predict change in one signal given a change in another signal (Brillinger, 1981; Halliday et al., 1995). Coherence can take values between 0 and 1 , with 0 indicating non-linearly related signals and 1 corresponding to identical signals. A marked coherence was observed with a peak around $3 \mathrm{~Hz}$ which was considerably larger for the error trials.
$\mathrm{Ncl}$ accumbens. The pretest revealed an exceedingly high ERN, typical for patients with OCD patients (Gehring et al., 2000) which indicates excessive action monitoring in OCD. This interpretation is corroborated by the fact that post-error slowing, as a sign of behavioural adaptation (Rabbitt, 1966), was much more pronounced in the patient ( $\sim 70 \mathrm{~ms})$ than in a group of normal controls ( $\sim 25 \mathrm{~ms})$.

During the operation, a clear ERN was seen in the surface recordings. Local field potentials from the depth electrodes showed error-related modulations in the $\mathrm{Ncl}$ accumbens but not from a position $5 \mathrm{~mm}$ above the target (see Figure 2B). Moreover, error-related activity in the $\mathrm{Ncl}$ accumbens preceded surface activity by $40 \mathrm{~ms}$ and coherence analysis (Figure 2C) showed a higher correlation for error than correct trials in the frequency band of the ERN between the $\mathrm{Ncl}$ accumbens and the scalp surface. The time-delay between depth and surface activity and the fact that no error-modulation was seen in the recording $5 \mathrm{~mm}$ above target argue for a local origin of the error-related activity in the $\mathrm{Ncl}$ accumbens as volume conductance could not induce a time-shift of the observed magnitude.

These results were interpreted as indicating a specific involvement of the $\mathrm{Ncl}$ accumbens in error processing and action monitoring. The error signals received by the $\mathrm{Ncl}$ accumbens might be used to weigh the information coming from the different inputs illustrated in the middle section of Figure 1 resulting in an adjustment of response strategies.

\section{A RESEARCH AGENDA}

The recent upsurge of deep brain stimulation surgery and its extension to brain structures highly relevant for the regulation of motor behavior, motivation and memory provides a unique chance for cognitive neuroscientists. To make full use of this new window on brain functions investigations should

- employ paradigms derived from neuroanatomical and cognitive models involving the target structure

- be carried out in the context of a multimodal (fMRI, ERP) imaging approach

- relate intracerebral electrical activity with parallel surface recordings in order to delineate the functional relationships between cortical and subcortical regions.

Obviously, this new approach has its own problems. First, the choice of the stimulation site is dictated by clinical considerations and thus a great number of potentially interesting target areas will stay out of limits for cognitive neuroscientists. Second, the target structures harbor functionally and neuroanatomically distinct subareas, such that recordings may or may not be made from the relevant area. Third, the targets 
have been singled out because the disease of the patient leads to dysfunction of the target which is intended to be normalized by DBS. This is apparent in particular in Parkinson's disease, where it has been shown that neurons in the subthalamic nucleus and the globus pallidus internus fire at increased rates and with oscillatory burst-like patterns (Bergman et al., 1994; Filion and Tremblay, 1991). This indicates that recordings from these structures may be partially altered by the disease. While the extent of functional alterations of the target structure may be smaller in, say, the $\mathrm{Ncl}$ accumbens in OCD or depressive patients, these conditions have been associated with abnormal reward processing in the literature and thus, again, results from depth recordings in these patients should be viewed as just one piece in a jig-saw puzzle which need corroborating evidence from multiple methodologies.

\section{CONFLICT OF INTEREST STATEMENT}

The authors declare that the research was conducted in the absence of any commercial or financial relationships that could be construed as a potential conflict of interest.

\section{ACKNOWLEDGMENTS}

This work was supported by grants from the BMBF to TFM, HJH and VS, and grants from the DFG (Sonderforschungsbereich 779) to TFM and HJH.

\section{REFERENCES}

Adcock, R. A., Thangavel, A., Whitfield-Gabrieli, S., Knutson, B., and Gabrieli, J. D. (2006). Reward-motivated learning: mesolimbic activation precedes memory formation. Neuron 50, 507-517.

Alexander, G. E., DeLong, M. R., and Strick, P. L. (1986). Parallel organization of functionally segregated circuits linking basal ganglia and cortex. Annu. Rev. Neurosci. 9, 357-381.

Androulidakis, A. G., Khan, S., Litvak, V., PleydellPearce, C. W., Brown, P., and Gill, S. S. (2008). Local field potential recordings from the pedunculopontine nucleus in a Parkinsonian patient. Neuroreport 19, 59-62.

Ashby, P., and Rothwell, J.C. (2000). Neurophysiologic aspects of deep brain stimulation. Neurology 55, S17-S20.

Astolfi, L., Cincotti, F., Mattia, D., Mattiocco, M., De Vico, F. F., Colosimo, A., Marciani, M. G., Hesse, W., Zemanova, L., Lopez, G. Z., Kurths, J., Zhou, C., and Babiloni, F. (2006). Estimation of the time-varying cortical connectivity patterns by the adaptive multivariate estimators in high resolution EEG studies. Conf. Proc. IEEE Eng Med. Biol. Soc. 1, 2446-2449.

Benabid, A. L. (2007). What the future holds for deep brain stimulation. Expert. Rev. Med. Devices 4, 895-903.

Benabid, A. L., Wallace, B., Mitrofanis, J., Xia, R., Piallat, B., Chabardes, S., and Berger, F. (2005). A putative generalized model of the effects and mechanism of action of high frequency electrical stimulation of the central nervous system. Acta Neurol. Belg. 105, 149-157.

Bergman, H., Wichmann, T., Karmon, B., and DeLong, M. R. (1994). The primate subthalamic nucleus. II. Neuronal activity in the MPTP model of parkinsonism. J. Neurophysiol. 72, 507-520.

Brillinger, D. R. (1981). Time Series - Data Analysis and Theory, 2nd edn. San Francisco, CA, Holden Day.

Bussone, G., Franzini, A., Proietti, C. A., Mea, E., Curone, M., Tullo, V., Broggi, G., Casucci, G., Bonavita, V., and Leone, M. (2007). Deep brain stimulation in craniofacial pain: seven years' experience. Neurol. Sci. 28(Suppl. 2), S146-S149.
Cohen, M. X., Elger, C. E., and Ranganath, C. (2007). Reward expectation modulates feedback-related negativity and EEG spectra. Neuroimage 35, 968-978.

Devos, D., Szurhaj, W., Reyns, N., Labyt, E., Houdayer, E., Bourriez, J. L., Cassim, F., Krystkowiak, P., Blond, S., Destee, A., Derambure, P., and Defebvre, L. (2006). Predominance of the contralateral movementrelated activity in the subthalamo-cortical loop. Clin. Neurophysiol. 117, 2315-2327.

Diederich, N. J., Verhagen, M. L., Bakay, R. A., and Alesch, F. (2008). Ventral intermediate thalamic stimulation in complex tremor syndromes. Stereotact. Funct. Neurosurg. 86, 167-172.

Dillon, D. G., Holmes, A. J., Jahn, A. L., Bogdan, R., Wald, L. L., and Pizzagalli, D. A. (2008). Dissociation of neural regions associated with anticipatory versus consummatory phases of incentive processing. Psychophysiology 45, 36-49.

Dinner,D.S., Neme, S., Nair,D., Montgomery, E. B., Jr., Baker, K. B., Rezai, A., and Luders, H. O. (2002). EEG and evoked potential recording from the subthalamic nucleus for deep brain stimulation of intractable epilepsy. Clin. Neurophysiol. 113, 1391-1402.

Falkenstein, M., Hoormann, J., and Hohnsbein, J. (1999). ERP components in Go/Nogo tasks and their relation to inhibition. Acta Psychol. (Amst) 101, 267-291.

Filion, M., and Tremblay, L. (1991). Abnormal spontaneous activity of globus pallidus neurons in monkeys with MPTP-induced parkinsonism. Brain Res. 547, 142-151.

Fogelson, N., Pogosyan, A., Kühn, A. A., Kupsch, A., van, B. G., Speelman, H., Tijssen, M., Quartarone, A., Insola, A., Mazzone, P., Di, L. V., Limousin, P., and Brown, P. (2005). Reciprocal interactions between oscillatory activities of different frequencies in the subthalamic region of patients with Parkinson's disease. Eur. J. Neurosci. 22, 257-266.

Frank, M. J. (2006). Hold your horses: a dynamic computational role for the subthalamic nucleus in decision making. Neural Netw. 19, 1120-1136.

Frank, M. J., Seeberger, L. C., and O'reilly, R. C. (2004). By carrot or by stick: cognitive reinforcement learning in parkinsonism. Science 306, 1940-1943.
Gehring, W. J., Himle, J., and Nisenson, L. G. (2000). Action-monitoring dysfunction in obsessivecompulsive disorder. Psychol. Sci. 11, 1-6.

Gerschlager, W., Alesch, F., Cunnington, R., Deecke, L., Dirnberger, G., Endl, W., Lindinger, G., and Lang, W. (1999). Bilateral subthalamic nucleus stimulation improves frontal cortex function in Parkinson's disease. An electrophysiological study of the contingent negative variation. Brain 122(Pt 12), 2365-2373.

Goto, Y., and Grace, A. A. (2005). Dopaminergic modulation of limbic and cortical drive of nucleus accumbens in goal-directed behavior. Nat. Neurosci. 8, 805-812.

Grace, A. A. (2000). Gating of information flow within the limbic system and the pathophysiology of schizophrenia. Brain Res. Brain Res. Rev. $31,330-341$.

Grace, A. A., Floresco, S. B., Goto, Y., and Lodge, D. J. (2007). Regulation of firing of dopaminergic neurons and control of goal-directed behaviors. Trends Neurosci. 30, 220-227.

Halliday, D. M., Rosenberg, J. R., Amjad, A. M., Breeze, P., Conway, B. A., and Farmer, S. F. (1995). A framework for the analysis of mixed time series/ point process data-theory and application to the study of physiological tremor, single motor unit discharges and electromyograms. Prog. Biophys. Mol. Biol. 64, 237-278.

Holroyd, C. B., and Coles, M. G. H. (2002). The neural basis of human error processing: reinforcement learning, dopamine, and the error-related negativity. Psychol. Rev. 109, 679-709.

Juergens, E., Guettler, A., and Eckhorn, R. (1999). Visual stimulation elicits locked and induced gamma oscillations in monkey intracortical- and EEG-potentials, but not in human EEG. Exp. Brain Res. 129, 247-259.

Karama, S., Lecours, A. R., Leroux, J. M., Bourgouin, P., Beaudoin, G., Joubert, S., and Beauregard, M. (2002). Areas of brain activation in males and females during viewing of erotic film excerpts. Hum. Brain Mapp. 16, 1-13.

Kelley, A. E. (2004). Memory and addiction: shared neural circuitry and molecular mechanisms. Neuron 44, 161-179.

Krämer, U. M., Cunillera, T., Camara, E., MarcoPallares, J., Cucurell, D., Nager, W., Bauer, P., 
Schule, R., Schols, L., Rodriguez-Fornells, A., and Munte, T. F. (2007). The impact of catecholO-methyltransferase and dopamine D4 receptor genotypes on neurophysiological markers of performance monitoring. J. Neurosci. 27, 14190-14198.

Kühn, A. A., Trottenberg, T., Kivi, A., Kupsch, A. Schneider, G. H., and Brown, P. (2005). The relationship between local field potential and neuronal discharge in the subthalamic nucleus of patients with Parkinson's disease. Exp. Neurol. 194, 212-220.

Kühn, J., Lenartz, D., Mai, J. K., Huff, W., Lee, S. H., Koulousakis, A., Klosterkoetter, J., and Sturm, V. (2007). Deep brain stimulation of the nucleus accumbens and the internal capsule in therapeutically refractory Tourette-syndrome. J. Neurol. 254, 963-965.

Lisman, J. E., and Grace, A. A. (2005). The hippocampal-VTA loop: controlling the entry of information into long-term memory. Neuron 46, 703-713.

Luu, P., and Tucker, D. M. (2001). Regulating action: alternating activation of midline frontal and motor cortical networks. Clin. Neurophysiol. 112, 1295-1306.

Magill, P. J., Sharott, A., Bevan, M. D., Brown, P., and Bolam, J. P. (2004a). Synchronous unit activity and local field potentials evoked in the subthalamic nucleus by cortical stimulation. J. Neurophysiol. 92, 700-714.

Magill, P. J., Sharott, A., Bolam, J. P., and Brown, P. (2004b). Brain state-dependency of coherent oscillatory activity in the cerebral cortex and basal ganglia of the rat. J. Neurophysiol. 92, 2122-2136.

Marco-Pallares, J., Cucurell, D., Cunillera, T., Garcia, R., Andres-Pueyo, A., Munte, T. F., and Rodriguez-Fornells, A. (2008). Human oscillatory activity associated to reward processing in a gambling task. Neuropsychologia 46, 241-248.

Marco-Pallares, J., Muller, S. V., and Munte, T. F. (2007). Learning by doing: an fMRI study of feedback-related brain activations. Neuroreport 18, 1423-1426.

McClure, S. M., Laibson, D. I., Loewenstein, G., and Cohen, J. D. (2004). Separate neural systems value immediate and delayed monetary rewards. Science 306, 503-507.

Middleton, F. A., and Strick, P. L. (2000). Basal ganglia output and cognition: evidence from anatomical, behavioral, and clinical studies. Brain Cogn. 42, 183-200.

Münte, T., Heldmann, M., Hinrichs, H., MarcoPallares, J., Krämer, U., Sturm, V., and Heinze, H. J.
(2008). Nucleus accumbens is involved in human action monitoring: evidence from invasive electrophysiological recordings. Front. Hum. Neurosci. 1, 11.

Peppe, A., Gasbarra, A., Stefani, A., Chiavalon, C., Pierantozzi, M., Fermi, E., Stanzione, P., Caltagirone, C., and Mazzone, P. (2008). Deep brain stimulation of $\mathrm{CM} / \mathrm{PF}$ of thalamus could be the new elective target for tremor in advanced Parkinson's Disease? Parkinsonism Relat. Disord. [Epub ahead of print].

Plaha, P., Ben-Shlomo, Y., Patel, N. K., and Gill, S. S. (2006). Stimulation of the caudal zona incerta is superior to stimulation of the subthalamic nucleus in improving contralateral parkinsonism. Brain 129, 1732-1747.

Rabbitt, P. M. (1966). Errors and error correction in choice-response tasks. J. Exp. Psychol. 71, 264-272.

Sasaki, K., and Gemba, H. (1986). Electrical activity in the prefrontal cortex specific to no-go reaction of conditioned hand movement with colour discrimination in the monkey. Exp. Brain Res. 64, 603-606.

Schiff, N. D., Giacino, J. T., Kalmar, K., Victor, J. D., Baker, K., Gerber, M., Fritz, B., Eisenberg, B., Biondi, T., O'Connor, J., Kobylarz, E. J., Farris, S., Machado, A., McCagg, C., Plum, F., Fins, J. J., and Rezai, A. R. (2007). Behavioural improvements with thalamic stimulation after severe traumatic brain injury. Nature 448, 600-603.

Schlaepfer, T. E., Cohen, M. X., Frick, C., Kosel, M., Brodesser, D., Axmacher, N., Joe, A. Y., Kreft, M., Lenartz, D., and Sturm, V. (2008). Deep brain stimulation to reward circuitry alleviates anhedonia in refractory major depression. Neuropsychopharmacol. 33, 368-377.

Schultz, W. (2006). Behavioral theories and the neurophysiology of reward. Annu. Rev. Psychol. 57, 87-115.

Schultz, W., Dayan, P., and Montague, P. R. (1997). A neural substrate of prediction and reward. Science 275, 1593-1599.

Smeets, P. A., de, G. C., Stafleu, A., van Osch, M. J., and van der, G. J. (2005). Functional magnetic resonance imaging of human hypothalamic responses to sweet taste and calories. Am. J. Clin. Nutr. 82, 1011-1016.

Sturm, V., Lenartz, D., Koulousakis, A., Treuer, H., Herholz, K., Klein, J. C., and Klosterkotter, J. (2003). The nucleus accumbens: a target for deep brain stimulation in obsessive-compulsive- and anxietydisorders. J. Chem. Neuroanat. 26, 293-299.

Supp, G. G., Schlogl, A., Trujillo-Barreto, N., Muller, M. M., and Gruber, T. (2007). Directed cortical information flow during human object recognition: analyzing induced EEG gammaband responses in brain's source space. PLoS ONE 2, e684.

Swanson, L. W. (2000). Cerebral hemisphere regulation of motivated behavior. Brain Res. 886, 113-164.

Ullsperger, M., and von Cramon, D. Y. (2003). Error monitoring using external feedback: specific roles of the habenular complex, the reward system, and the cingulate motor area revealed by functional magnetic resonance imaging. J. Neurosci. 23, 4308-4314.

Valls-Sole, J., Compta, Y., Costa, J., Valldeoriola, F., and Rumia, J. (2008). Human central nervous system circuits examined through the electrodes implanted for deep brain stimulation. Clin. Neurophysiol. 119, 1219-1231.

Wendt, M., Heldmann, M., Munte, T. F., and Kluwe, R. H. (2007). Disentangling sequential effects of stimulus- and response-related conflict and stimulus-response repetition using brain potentials. J. Cogn. Neurosci. 19, 1104-1112.

Wennberg, R., and Lozano, A. M. (2006). Restating the importance of bipolar recording in subcortical nuclei. Clin. Neurophysiol. 117, 474-475.

Wittmann, B. C., Bunzeck, N., Dolan, R. J., and Duzel, E. (2007). Anticipation of novelty recruits reward system and hippocampus while promoting recollection. Neuroimage 38, 194-202.

Yacubian, J., Glascher, J., Schroeder, K., Sommer, T., Braus, D. F., and Buchel, C. (2006). Dissociable systems for gain- and loss-related value predictions and errors of prediction in the human brain. J. Neurosci. 26, 9530-9537.

Yu, H., and Neimat, J. S. (2008). The treatment of movement disorders by deep brain stimulation. Neurotherapeutics 5, 26-36.

Zrinzo, L., Zrinzo, L., and Hariz, M. (2007). The peripeduncular nucleus: a novel target for deep brain stimulation? Neuroreport 18, 1631-1632.

Received: 25 April 2008; accepted: 03 June 2008.

Citation: Front. Neurosci. (2008) 2, 1: 72-78, doi: 10.3389/neuro.01.006.2008

Copyright $\odot 2008$ Münte, Heldmann, Hinrichs, Marco-Pallares, Krämer, Sturm and Heinze. This is an open-access article subject to an exclusive license agreement between the authors and the Frontiers Research Foundation, which permits unrestricted use, distribution, and reproduction in any medium, provided the original authors and source are credited. 